\title{
Emergency Department Visits for Heat Stroke in the United States, 2009 and 2010
}

\author{
Xian Wu', Joanne E Brady ${ }^{1,2}$, Henry Rosenberg ${ }^{3,4}$ and Guohua Li $i^{1,2,5^{*}}$
}

\begin{abstract}
Background: The effect of extreme heat on health has become a growing public health concern due to climate change. We aimed to examine the epidemiological patterns of hospital-based emergency department (ED) visits for heat stroke in the United States.

Findings: We analyzed data from the 2009 and 2010 Nationwide Emergency Department Sample, the largest ED data system sponsored by the Agency for Healthcare Research and Quality. ED visits for heat stroke were identified by screening the recorded diagnoses using the International Classification of Diseases, Ninth Revision, Clinical Modification (ICD-9-CM) code 992.0. Annual incidence rates of ED visits for heat stroke were computed according to demographic characteristics and geographic regions. In 2009 and 2010, there were an estimated 8,251 ED visits for heat stroke in the United States, yielding an annual incidence rate of 1.34 visits per 100,000 population (95\% Confidence Interval $[\mathrm{Cl}]=1.23-1.45$ ). Significantly higher incidence rates were found in males (1.99 per 100,000; $95 \%$ $\mathrm{Cl}=1.82-2.16$ ), adults aged $\geq 80$ years $(4.45$ per 100,$000 ; 95 \% \mathrm{Cl}=3.73-5.18)$, and residents living in the southern region (1.61 per 100,000; $95 \% \mathrm{Cl}=1.43-1.79$ ). The majority (63.1\%) of ED visits for heat stroke occurred during the summer months of June, July and August. Over one-half (54.6\%) of the ED visits for heat stroke required hospitalization and $3.5 \%$ of the patients died in the ED or hospital.

Conclusions: Heat stroke results in approximately 4,100 ED visits each year in the United States, with the majority occurring in the summer months and requiring admission to the hospital. Men, the elderly, and people living in the south region are at heightened risk.
\end{abstract}

Keywords: Emergency medical service; Epidemiology; Global warming; Heat stroke; Public health

\section{Introduction}

Heat stroke is a severe form of heat illness with potentially grave outcomes (Knowlton et al. 2009). Clinically, heat stroke is defined as a core body temperature that rises above $40^{\circ} \mathrm{C}$, accompanied by hot, dry skin and central nervous system abnormalities such as delirium, convulsions, or coma (Bouchama and Knochel 2002). Heat stroke is characterized by a patient's inability to transfer heat produced from normal metabolic activity or exercise to the environment, which results in hyperthermia and cellular injury (Jardine 2007). Hyperthermia can be extremely harmful and potentially fatal because a

\footnotetext{
* Correspondence: gl2240@cumc.columbia.edu

'Department of Epidemiology, Columbia University Mailman School of Public Health, New York, NY, USA

${ }^{2}$ Department of Anesthesiology, Columbia University College of Physicians and Surgeons, New York, NY, USA

Full list of author information is available at the end of the article
}

prolonged elevation in core temperature - over $40^{\circ} \mathrm{C}$ lasting 30-60 minutes - may exceed the ability for the cells to tolerate the thermal stress leading to multi-organ tissue damage (Kerr et al. 2013). Therefore, heat stroke often requires emergency care in order to obtain prompt and aggressive interventions and minimize long-term consequences.

Exposure to extreme heat is the main cause of heat stroke, especially during heat waves (Changnon et al. 1996). Predisposing factors of heat stroke include high ambient temperature, intense solar radiation, low level of physical fitness, sleep deprivation (Casa et al. 2012a), social isolation (Semenza et al. 1996), and lower access to air conditioning (O'Neill et al. 2005). Elderly adults and people with cardiovascular and respiratory disease, diabetes, obesity and the use of medications that reduce sweating, impair thermoregulation, and weaken cardiovascular response are at higher risk from heat stroke 
(Bonauto et al. 2007). With increasing frequency, duration, and intensity of heat waves both globally and in the United States, heat stroke could become a health threat to a larger population in the future and pose a greater burden on the healthcare system (Meehl and Tebaldi 2004).

Previous epidemiological studies of heat stroke or other heat-related illness were limited to selected population groups, such as athletes, mining workers and military personnel, and to outbreaks during heat waves (Bonauto et al. 2007; Semenza et al. 1996; Casa et al. 2012b; Armed Forces Health Surveillance Center 2013; Hunt et al. 2013). Little is known about the incidence and epidemiological patterns of heat stroke in the general population at a national level. We sought to close this research gap by drawing on recently available data from hospital-based emergency departments (EDs) in the United States. Information about the epidemiologic patterns of ED visits for heat stroke may help assist public health professionals and emergency medical personnel to identify high-risk population groups and develop effective preventive strategies and clinical interventions.

\section{Findings \\ Methods}

Data source

Data for this study came from the Nationwide Emergency Department Sample (NEDS) for 2009 and 2010. The NEDS dataset is part of the Healthcare Cost and Utilization Project sponsored by the Agency for Healthcare Research and Quality. NEDS is the largest all-payer ED database, containing approximately a $20 \%$ stratified sample of all US hospital-based EDs and (Agency for Healthcare Research and Quality 2014a). In 2009, 964 hospitals in 29 states contributed data to NEDS and in 2010, 961 hospitals in 28 states contributed data to NEDS. This database captures discharge information for ED visits as well as inpatient information on ED patients admitted into the same hospital. NEDS records data for each visit on more than 100 variables, including patient demographic characteristics, hospital characteristics, up to 19 diagnoses documented during the ED visit and subsequent hospitalization, procedures performed during hospitalization, disposition from the ED, insurance status and total charges for ED service.

NEDS uses a stratified, single-stage cluster sampling procedure to obtain a nationally representative sample of hospital-based ED visits. Sample stratification is based on five hospital characteristics: geographic region, trauma center designation, urban-rural location of the hospital, teaching status and hospital ownership type. Sampling weights assigned to individual visits allow for national estimates of all hospital-based ED visits. Population data from the US Census Bureau for July 1, 2009, and April 1, 2010 were added up as the denominator when calculating incidence rates, which were expressed as ED visits for heat stroke per 100,000 population per year (U.S. Census Bureau 2010, 2011).

\section{Study variables}

For each visit, up to 19 diagnoses were recorded and coded with the International Classification of Diseases, Ninth Revision, Clinical Modification (ICD-9-CM) codes. ED visits for heat stroke and sun stroke were identified by screening for the corresponding ICD-9-CM code (992.0) in any of the nineteen recorded diagnoses. Excluded from the study were other heat-related illnesses (ICD-9-CM codes 992.1-992.9), such as heat syncope, heat cramps, and heat exhaustion, which are less severe than heat stroke and are likely more susceptible than heat stroke to biases from socioeconomic status, healthcare seeking behavior, and misclassification. Age in years was categorized into the following groupings: 0-19, 20-29, 30-39, 40-49, $50-59,60-69,70-79$ and $\geq 80$. We also assessed the following variables: sex, urban-rural status, month of visit, diagnosis, and disposition from the ED. Urban-rural status was based on the Office of Management and Budget (OMB) metropolitan/micropolitan assignment of U.S. counties as updated through the 2005 revisions (Agency for Healthcare Research and Quality 2008a). Geographic region is defined by the US Census Bureau (Agency for Healthcare Research and Quality 2008b). The presence of comorbid conditions was identified using the Clinical Classification Software (CCS) codes that combine similar ICD-9-CM codes (Agency for Healthcare Research and Quality 2014b).

\section{Data analysis}

Heat stroke visits were weighted to estimate national incidence rates by demographic characteristics and geographic region. Standard errors and corresponding 95\% confidence intervals for these national estimates were computed using methodology that accounts for the complex survey design properties for variance estimation (Chen and Gorrell 2008). This method is recommended by HCUP accounting for the complex survey design (Houchens and Elixhauser 2005). All statistical analyses were performed with SAS Version 9.3 (SAS Institute, Cary, NC). This study was approved by the Columbia University Medical Center institutional review board.

\section{Results}

In 2009 and 2010, there were an estimated total of 8,251 ED visits for heat stroke, exclusive of 101,995 ED visits for unspecified heat exhaustion and 39,142 ED visits for other heat-related illnesses. The estimated annual incidence rate of heat stroke was 1.34 visits per 100,000 population $(95 \% \mathrm{CI}=1.23-1.45)$ (Table 1$)$. Over one-fifth 
Table 1 Incidence rates and $95 \%$ confidence intervals (Cls) of heat stroke emergency department visits by patient characteristics, National Emergency Department Sample, United States, 2009 and 2010

\begin{tabular}{|c|c|c|c|}
\hline $\begin{array}{l}\text { Patient } \\
\text { characteristics }\end{array}$ & $\begin{array}{l}\text { Number of patients with } \\
\text { heat stroke (weighted) }\end{array}$ & $\begin{array}{c}\text { Incidence per } \\
100000 \\
\text { population }\end{array}$ & $95 \% \mathrm{Cl}$ \\
\hline Total population & 8251 & 1.34 & $1.23-1.45$ \\
\hline \multicolumn{4}{|l|}{ Age(yr) } \\
\hline 0-19 & 801 & 0.48 & $0.40-0.56$ \\
\hline $20-29$ & 987 & 1.15 & $0.93-1.37$ \\
\hline $30-39$ & 927 & 1.15 & $0.97-1.34$ \\
\hline $40-49$ & 1281 & 1.47 & $1.26-1.67$ \\
\hline $50-59$ & 1342 & 1.62 & $1.35-1.89$ \\
\hline $60-69$ & 1118 & 1.97 & $1.61-2.32$ \\
\hline $70-79$ & 785 & 2.38 & $1.98-2.79$ \\
\hline $80+$ & 1010 & 4.45 & $3.73-5.18$ \\
\hline \multicolumn{4}{|l|}{ Sex } \\
\hline Male & 6022 & 1.99 & $1.81-2.16$ \\
\hline Female & 2219 & 0.71 & $0.63-0.79$ \\
\hline \multicolumn{4}{|l|}{ Region of hospital } \\
\hline Northeast & 890 & 0.80 & $0.65-0.96$ \\
\hline Midwest & 1555 & 1.16 & $0.97-1.35$ \\
\hline South & 3675 & 1.61 & $1.43-1.79$ \\
\hline West & 2132 & 1.49 & $1.19-1.78$ \\
\hline \multicolumn{4}{|l|}{ Patient location } \\
\hline Metropolitan & 6303 & 1.19 & $1.08-1.30$ \\
\hline Micropolitan & 953 & 1.55 & $1.24-1.87$ \\
\hline \multicolumn{4}{|l|}{ Year of visit ${ }^{a}$} \\
\hline 2009 & 3294 & 1.07 & $0.94-1.21$ \\
\hline 2010 & 4957 & 1.61 & $1.43-1.78$ \\
\hline
\end{tabular}

Note. Year of visit was defined as discharge year. There were 5 missing values for sex.

(21.7\%) of the ED visits for heat stroke were made by patients aged 70 years and older. The incidence rates for heat stroke ED visits increased with age and were the highest for those aged 80 years or older (4.45 visits per 100,000; 95\% CI $=3.73-5.18$ ).

Males accounted for nearly three quarters $(73.2 \%)$ of all ED visits for heat stroke. Overall, the annual incidence rate of ED visits for heat stroke for males (1.99 visits per $100,000 ; 95 \% \mathrm{CI}=1.81-2.16)$ was 2.8 times the rate for females (0.71 visits per 100,000 95\% CI $=0.63-0.79)$. Residents in the South had the highest incidence rate of ED visits for heat stroke (1.61 visits per 100,000 ; $95 \% \mathrm{CI}=1.43$ 1.79) while those living in the Northeast had the lowest rate (0.80 visits per 100,$000 ; 95 \% \mathrm{CI}=0.65-0.96$ ). Incidence rates of ED visits for heat stroke were similar between urban areas (1.19 visits per 100,000; $95 \% \mathrm{CI}=1.08-1.30)$ and rural areas ( 1.55 visits per 100,$000 ; 95 \% \mathrm{CI}=1.24-1.87$ ).
As expected, ED visits for heat stroke showed an apparent seasonality, with almost two thirds $(63.1 \%)$ of the visits occurring in the summer from June to August (Figure 1). Exclusive of the heat stroke diagnosis, a total of 53,270 comorbidities were recorded for all heat stroke ED visits. Fluid and electrolyte disorders (CCS code 56) were the most frequent presenting comorbidity (11.4\%), followed by acute and unspecified renal failure (CCS code $157,4.4 \%$ ), other connective tissue disease (CCS code 211, 4.2\%), and essential hypertension (CCS code 98, 4.1\%).

Over half (54.6\%) of the patients who had an ED visit for heat stroke were admitted to hospitals, $37.8 \%$ were treated and released and 3.5\% died (including 48 patients who died in the ED and 238 patients who died in hospital). The admission rate and case fatality rate for heat stroke ED visits were much higher than for other ED visits (15.2\% and $0.6 \%$, respectively).

\section{Discussion}

This analysis provides valuable information for understanding the epidemiologic patterns of ED visits for heat stroke in the United States. The results indicate that, each year in the United States, there are an estimated 4,126 ED visits for heat stroke, with an annual national incidence rate of 1.34 visits per 100,000 population and a case fatality of $3.5 \%$. In previous studies, the case fatality of classical heat stroke ranged from less than $10 \%$ to 64\% (Yaqub and Al Deeb 1998; Jimenez-Mejias et al. 1990). The lower case fatality reported in the present study is likely due to the fact that it included only patients treated in the EDs and the most severe cases of heat stroke often result in death at the scene.

This study confirms that the elderly are at heightened risk of heat stroke (Jardine 2007; Semenza et al. 1996). We also found that males are 2.80 times as likely as females to be treated for heat stroke. One previous study reported that being male was a major risk factor of dying from classical heat illness (Stafoggia et al. 2006). In contrast, a study conducted in soldiers found that heat illness risk was significantly greater in women than in men (Carter et al. 2005). Data from a heat wave surveillance system in Korea also showed that women were at a higher risk of dying from heat stroke than men (Na et al. 2013). These seemingly conflicting findings are likely due to the differences in study populations and outcome measures.

Our results indicate that over one-half $(63.1 \%)$ of all ED visits for heat stroke occur in the summer months of June, July and August whereas $0.9 \%$ of them arise in the winter months of December, January and February. This finding is consistent with previous reports that risk for heat illness is a function of ambient temperature, relative humidity, wind speed, and solar radiant heat ( $\mathrm{Yu}$ et al. 2012; Murakami et al. 2012). In addition, the geographical differences in the incidence rates of ED visits for 


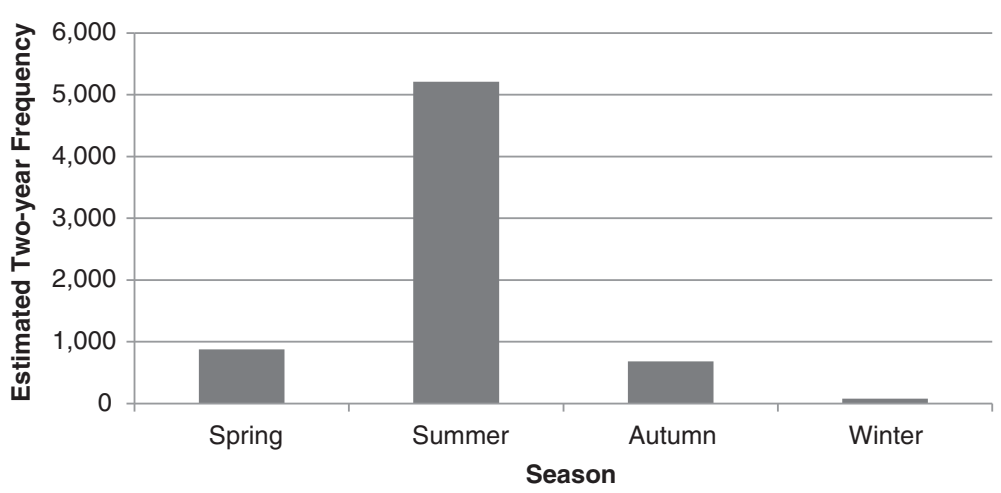

Figure 1 Estimated two-year frequency of emergency department visits for heat stroke by season, United States, 2009 and 2010. Note: Monthly and yearly data are not presented as the report of data for any subgroup with 10 or fewer subjects is prohibited by the HCUP NEDS data use agreement. There were 1408 missing values for admission month, 93.7\% of which are from hospitals in the southern states.

heat stroke also support the relation between ambient temperature and heat stroke.

Comorbid conditions of heat stroke ED visits reported in our study are similar to those found in previous studies (Jardine 2007; NYC Department of Health and Mental Hygiene 2006; Wheeler et al. 2013). Specifically, the most commonly recorded comorbid condition is fluid and electrolyte disorders, followed by acute and unspecified renal failure, other connective tissue disease, and essential hypertension. It is plausible that some of these comorbid conditions, e.g., fluid and electrolyte disorders and unspecified renal failure, might be in fact the consequences of heat stroke rather than preexisting conditions.

Our study also reveals that heat stroke as a medical emergency is significantly more severe than other emergencies as a whole, with a 2.6-fold increase in the admission rate and a 4.8 -fold increase in case fatality. Clinical management of heat stroke often requires aggressive interventions such as cold water immersion and chilled intravenous fluids to low core body temperature as rapidly as possible (Bouchama et al. 2007). Multi-organ dysfunction as a common complication may contribute to the excess case fatality of heat stroke (Pease et al. 2009).

\section{Limitations}

Our study has several notable limitations. First, the incidence rates of heat stroke are likely to be underestimated since our study was limited to patients presenting to the EDs. Many heat stroke patients, especially those severe cases that progress rapidly, may die before reaching any medical facility. On the other hand, some less severe heat stroke cases might be misclassified as other heat-related illnesses, such as heat syncope or heat exhaustion. Excluded from our analysis were 141,137 ED visits for other heat-related illnesses during the two-year study period. Second, the NEDS does not capture some important demographic information, such as race/ ethnicity and marital status. Previous studies indicate that those geographically or socially isolated are particularly vulnerable to heat stroke (Semenza et al. 1996). Finally, the NEDS does not contain a unique identification number for each patient. Thus, it is impossible to account for multiple visits made by a single patient.

\section{Conclusions}

Our study provides valuable data for understanding the magnitude and epidemiologic patterns of heat stroke on a national level. With global warming, there might be a rise in the frequency and severity of extreme heat waves in the United States and elsewhere. Thereby, heat stroke and other heat-related illnesses could become a health threat to a larger population and a medical emergency of increasing importance. It is necessary to strengthen the surveillance of heat-related disorders and develop effective intervention programs to reduce the adverse health consequences of global warming and extreme heat.

\section{Abbreviations}

ED: Emergency department; ICD-9-CM: International Classification of Diseases, Ninth Revision, Clinical Modification; Cl: Confidence interval:

NEDS: Nationwide Emergency Department Sample; OMB: Office of Management and Budget; CCS: Clinical Classification Software.

\section{Competing interests}

This research was supported in part by the Malignant Hyperthermia Association of the United States and the National Center for Injury Prevention and Control of the Centers for Disease Control and Prevention (Grant 1 R49 CE002096). The contents of the manuscript are solely the responsibility of the authors and do not necessarily reflect the official views of the funding agencies.

\section{Authors' contributions}

XW contributed to the study design, performed the statistical analysis, and wrote the first draft of the manuscript; JEB acquired the data, supervised computer programming and statistical analysis, and contributed to the critical revision of the manuscript; HR assisted with the study design, supervised the literature review, helped interpret the results, and contributed to the critical revision of the manuscript; and GL conceived of the study, secured funding, and provided oversight for the implementation of the 
research plan and the development of the manuscript. All authors read and approved the final manuscript.

\section{Acknowledgments}

The authors thank Barbara H. Lang, MPH, for her administrative and editorial assistance.

\section{Author details}

${ }^{1}$ Department of Epidemiology, Columbia University Mailman School of Public Health, New York, NY, USA. ²Department of Anesthesiology, Columbia University College of Physicians and Surgeons, New York, NY, USA. ${ }^{3}$ Department of Medical Education and Clinical Research, Saint Barnabas Medical Center, Livingston, NJ, USA. ${ }^{4}$ Malignant Hyperthermia Association of the United States, Sherburne, NY, USA. ${ }^{5}$ Center for Injury Epidemiology and Prevention, Columbia University Medical Center, 722 W. 168th Street, Room 524, New York 10032NY, USA.

Received: 19 November 2013 Accepted: 26 January 2014 Published: 24 April 2014

\section{References}

Agency for Healthcare Research and Quality. Clinical Classifications Software (CCS) for ICD-9-CM. Rockville, MD: Agency for Healthcare Research and Quality; 2014a. http://www.hcup-us.ahrq.gov/toolssoftware/ccs/ccs.jsp. Accessed 17 April 2014.

Agency for Healthcare Research and Quality. Overview of the Nationwide Emergency Department Sample (NEDS). Rockville, MD: Agency for Healthcare Research and Quality; 2014b. http://www.hcup-us.ahrq.gov/nedsoverview.jsp. Accessed 17 April 2014.

Agency for Healthcare Reserch and Quality. NEDS Description of Data Elements: Patient Location: NCHS Urban-Rural Code, 2006. Agency for Healthcare Research and Quality: Rockville, MD; 2008a. http://www.hcup-us.ahrq.gov/db/ vars/pl_nchs2006/nedsnote.jsp. Accessed 17 June 2013.

Agency for Healthcare Reserch and Quality. NEDS Description of Data Elements: Region of Hospital. Rockville, MD: Agency for Healthcare Research and Quality; 2008b. http://www.hcup-us.ahrq.gov/db/vars/pl_nchs2006/nedsnote. jsp. Accessed 17 June 2013

Armed Forces Health Surveillance Center. Update: Heat injuries, active component, U.S. Armed Forces, 2012. Msmr. 2013; 20(3):17-20.

Bonauto D, Anderson R, Rauser E, Burke B. Occupational heat illness in Washington State, 1995-2005. Am J Ind Med 2007; 50(12):940-50. doi:10.1002/ajim.20517.

Bouchama A, Knochel JP. Heat stroke. N Engl J Med 2002; 346(25):1978-88. doi:10.1056/NEJMra011089.

Bouchama A, Dehbi M, Chaves-Carballo E. Cooling and hemodynamic management in heatstroke: practical recommendations. Crit Care (London, England) 2007: 11(3):R54. doi:10.1186/cc5910.

Carter R III, Cheuvront SN, Williams JO, Kolka MA, Stephenson LA, Sawka MN, Amoroso PJ. Epidemiology of hospitalization and deaths from heat illness in soldiers. Med Sci Sports Exerc 2005; 37(8):1338-44.

Casa DJ, Armstrong LE, Kenny GP, O'Connor FG, Huggins RA. Exertional heat stroke: new concepts regarding cause and care. Curr Sports Med Rep 2012a; 11(3):115-23. doi:10.1249/JSR.0b013e31825615cc.

Casa DJ, Guskiewicz KM, Anderson SA, Courson RW, Heck JF, Jimenez CC, McDermott BP, Miller MG, Stearns RL, Swartz EE, Walsh KM. National athletic trainers' association position statement: preventing sudden death in sports. J Ath/ Train 2012b; 47(1):96-118.

Changnon SA, Kunkel KE, Reinke BC. Impacts and Responses to the 1995 Heat Wave: A Call to Action. Bull Am Meteorological Soc 1996; 77(7):1497-506. doi:10.1175/1520-0477(1996)077<1497:|ARTTH>2.0.CO;2.

Chen X, Gorrell P. An Introduction to the SAS Survey Analysis PROCS. NESUG 2008; 2008. http://www.nesug.org/proceedings/nesug08/sa/sa06.pdf. Accessed January 172014.

Houchens R, Elixhauser A. Final Report on Calculating Nationwide Inpatient Sample (NIS) Variances, 2001, HCUP Methods Series Report \#2003-2. Rockville, MD: Agency for Healthcare Research and Quality; 2005.

Hunt AP, Parker AW, Stewart IB. Symptoms of heat illness in surface mine workers. International archives of occupational and environmental health. 2013; 86(5):519-27. doi:10.1007/s00420-012-0786-0.

Jardine DS. Heat illness and heat stroke. Pediatr Rev 2007; 28(7):249-58.
Jimenez-Mejias ME, Montano Diaz M, Villalonga J, Bollain Tienda E, Lopez Pardo F, Pineda JA, González de la Puente MA. Classical heatstroke in Spain. Analysis of a series 78 cases. Medicina clinica. 1990; 94(13):481-6.

Kerr ZY, Casa DJ, Marshall SW, Comstock RD. Epidemiology of exertional heat illness among U.S. high school athletes. Am J Prev Med 2013; 44(1):8-14.

Knowlton K, Rotkin-Ellman M, King G, Margolis HG, Smith D, Solomon G, Trent R, English P. The 2006 California heat wave: impacts on hospitalizations and emergency department visits. Environ Health Perspect 2009: 117(1):61-7. doi:10.1289/ehp.11594.

Meehl GA, Tebaldi C. More intense, more frequent, and longer lasting heat waves in the 21st century. Science (New York, NY). 2004; 305(5686):994-7. doi:10.1126/science.1098704.

Murakami S, Miyatake N, Sakano N. Changes in air temperature and its relation to ambulance transports due to heat stroke in all 47 prefectures of Japan. J Prev Med Public Health 2012; 45(5):309-15.

Na W, Jang JY, Lee KE, Kim H, Jun B, Kwon JW, Jo SN. The effects of temperature on heat-related illness according to the characteristics of patients during the summer of 2012 in the Republic of Korea. J Prev Med Public Health 2013; 46(1):19-27.

New York City: Department of Health and Mental Hygiene. Deaths associated with heat waves in 2006. In: NYC Vital Signs Investigation Report. New York City: Department of Health and Mental Hygiene; 2006. http://www.nyc.gov/ $\mathrm{html} / \mathrm{doh} /$ downloads/pdf/survey/survey-2006heatdeaths.pdf. Accessed October 132013.

New York City: Department of Health and Mental Hygiene. Heat illness and death-New York City, 2000-2011. MMWR Morb Mortal Wkly Rep 2013; 62 (31):617-21.

New York City: Department of Health and Mental Hygiene. Vital signs: Deaths associated with heat waves in 2006. New York, NY: NYC Department of Health and Mental Hygiene; 2006.

O'Neill MS, Zanobetti A, Schwartz J. Disparities by race in heat-related mortality in four US cities: the role of air conditioning prevalence. J Urban Health 2005; 82(2):191-7. doi:10.1093/jurban/jti043.

Pease S, Bouadma L, Kermarrec N, Schortgen F, Regnier B, Wolff M. Early organ dysfunction course, cooling time and outcome in classic heatstroke. Intensive Care Med 2009; 35(8):1454-8. doi:10.1007/s00134-009-1500-x.

Semenza JC, Rubin CH, Falter KH, Selanikio JD, Flanders WD, Howe HL, Wilhelm $J$. Heat-related deaths during the July 1995 heat wave in Chicago. N Engl J Med 1996; 335(2):84-90. doi:10.1056/nejm199607113350203.

Stafoggia M, Forastiere F, Agostini D, Biggeri A, Bisanti L, Cadum E, Caranci N, de' Donato F, De Lisio S, De Maria M, Michelozzi P, Miglio R, Pandolfi P, Picciotto S, Rognoni M, Russo A, Scamato C, Perucci CA. Vulnerability to heat-related mortality: a multicity, population-based, case-crossover analysis. Epidemiology (Cambridge, Mass). 2006; 17(3):315-23. doi:10.1097/01. ede.0000208477.36665.34.

US Census Bureau. 2010 American Community Survey 1-Year Estimates. Washington, DC: US Census Bureau; 2010. http://factfinder2.census.gov/faces/ tableservices/jsf/pages/productview.xhtml? pid=ACS_10_1YR_DP05\&prodType=table. Accessed 13 July 2013.

US Census Bureau. Annual Estimates of the Population of Metropolitan and Micropolitan Statistical Areas: April 1, 2010 to July 1, 2011. Washington, DC: US Census Bureau; 2011. http://www.census.gov/popest/data/historical/2010s/ vintage_2011/metro.html. Accessed 13 July 2013.

Wheeler K, Lane K, Walters S, Matte T. Heat illness and deaths-New York City, 2000-2011. MMWR Morb Mortal Wkly Rep 2013; 62(31):617-21.

Yaqub B, Al DS. Heat strokes: aetiopathogenesis, neurological characteristics, treatment and outcome. J Neurol Sci 1998; 156(2):144-51.

Yu W, Mengersen K, Wang X, Ye X, Guo Y, Pan X, Tong S. Daily average temperature and mortality among the elderly: a meta-analysis and systematic review of epidemiological evidence. Int J Biometeorol 2012; 56(4):569-81. doi:10.1007/s00484-011-0497-3.

doi:10.1186/2197-1714-1-8

Cite this article as: Wu et al:: Emergency Department Visits for Heat

Stroke in the United States, 2009 and 2010. Injury Epidemiology 2014 1:8. 